\title{
Relación lengua y cultura en el Diccionario lingüístico etnográfico de la lengua Mapuche. Mapudungun-Español- English, de María Catrileo Chiguailaf
}

\section{CLAUDIA RODRÍGUEZ MONARCA}

\author{
Universidad Austral de Chile \\ claudiar@uach.cl
}

\begin{abstract}
Vivíamos con los abuelos, los tíos, los primos y demás parientes formando una enorme familia. Recuerdo que la ruca que teníamos era de grandes dimensiones, lo que permitía que en muchas oportunidades nos juntáramos entre 20 a 25 personas alrededor del fogón en las noches. A partir de este escenario familiar se producía toda una situación de conversación, de relatos, de tradiciones y muchas adivinanzas y, algo fundamental, una intensa práctica lingüística.
\end{abstract}

María Catrileo

Esta nota corresponde a la presentación del Diccionario de María Catrileo, en enero de 2018, en el marco de la clausura del Seminario de Literatura Regional, organizado por el Magíster en Literatura Hispanoamericana Contemporánea, realizado en el Auditorio del Edificio Eleazar Huerta. En esa misma sala tuvimos el privilegio de homenajear a María Catrileo el año 2004, en el contexto del Primer encuentro de poetas mujeres mapuches, "Meli domo dungu", cuatro palabras de mujer.

Como si fuese un déjà $v u$, volvemos, con el mismo respeto, admiración, amistad y cariño, a rendir un tributo a María Catrileo, sumándonos a otros numerosos homenajes recibidos a lo largo de su trayectoria, como el Premio Provincial de Conservación de Monumentos Nacionales, en mayo de 2004, en el marco de la conmemoración de la Semana del Patrimonio, distinción entregada por su labor de investigación, educación y conservación de la lengua mapudungún como patrimonio cultural y comunicacional del pueblo mapuche. Ese mismo año, la revista Austral de Ciencias Sociales $N^{\circ} 8$ publica una extensa entrevista que le realizan Ricardo Molina y Pía Poblete, en la que se asoma más la persona de María, con relatos de su infancia que recuerdan cómo eran los modos de transmisión de saberes, en torno a un fogón y su experiencia implementando el plan de educación intercultural bilingüe. Asimismo, el año 2010, la revista Estudios Filológicos 46, le dedica un apartado especial en su sección Documentos, con testimonios directos de los colegas Gilberto Sánchez, Rodrigo Moulian e Iván Carrasco. Todos ellos, reconocimientos 
por la tarea de docencia, investigación, difusión y revitalización del mapudungún. Trabajo sostenido y vigente que la mantiene, actualmente, vinculada a la Universidad Austral de Chile como coinvestigadora de los proyectos del Dr. Moulian, con estudios sobre las relaciones de interferencia del mapudungún con las lenguas andinas.

En esta presentación me tomaré la licencia para contextualizar el diccionario y dar una visión más amplia de su proyecto académico; de su visión de mundo, donde aparece indisoluble la relación lengua-cultura; de los tempos de maduración de un libro de esta envergadura de la mano de la justificación del método lingüístico etnográfico; de lo que significa la reedición del diccionario y la reedición desde Ediciones UACh; para finalmente referirme al diccionario, en términos de sus particularidades y ejemplificando con una de las situaciones comunicativas y con los campos semánticos en los que se detiene, las categorías gramaticales (sustantivos, verbos y adjetivos) relacionados con las enfermedades (y por ende con los remedios); ámbito particularmente interesante porque además del enfoque descriptivo, da cuenta y comparte otros saberes, como los de la medicina mapuche.

Para introducir el tema que nos convoca, quisiera leer un fragmento de un relato de Bernardo Colipán, poeta mapuche huilliche de Osorno: "La noche avanzaba con pasos ajenos y en las sombras dejaba un rastro que no era el mío. Pegadas a las ruedas de las carretas se ocultaba parte de la historia".

He querido partir con este epígrafe de Bernardo Colipán -que corresponde a un fragmento de "Mito y memoria en un Epeu Huilliche"- porque este breve texto concentra y trasunta el devenir de un proceso civilizatorio y de un horizonte colonial que es torcido imperceptiblemente, sin embargo, por la tozudez de una lengua, el mapudungún, y una cultura, la mapuche. De la invisibilización de la historia de un pueblo, como ocultada pero que se asoma en las ruedas de las carretas, da cuenta la historiografía mapuche, haciéndose cargo de quitar el velo a estas zonas grises de la historia oficial (Héctor Nahuelpan) y dejar un rastro propio (y no ajeno) en el camino. Contribuye a ello también la literatura y la lingüística, en ese gesto de reciprocidad y complementariedad entre disciplinas y saberes, como principios articuladores y orientadores del Küme Mogen, el buen vivir. Un ejemplo literario puede ser el poemario El mapa roto de Juan Wenuan Escalona, y un ejemplo lingüístico, La lengua mapuche en el Siglo XXI, de María Catrileo, ambos con títulos sugerentes que desafían y tensionan problemáticas territoriales y lingüísticas del presente.

Esta tarde nos convoca una "conversación intercultural", como dirá Ricardo Casas. La presentación de un hermoso libro, cuidado y prolijo desde todos sus ángulos, el Diccionario lingüistico etnográfico de la lengua Mapuche. Mapudungun-Español-English, de María Catrileo Chiguailaf, de Ediciones UACh. El gesto de la conversación se perfila en este mismo evento, en este acto que es a su vez performativo y perlocutivo, porque al hablar de la lengua, se va posicionando, y también porque la conversación es parte del método de investigación etnográfica con el que trabaja Catrileo en este libro.

Si bien hoy es una cita con la lingüística, particularmente con la lexicografía, no puedo dejar de establecer el diálogo virtuoso con la literatura, ya que provengo de esa área, y en particular de los estudios de las literaturas indígenas, a las que hay que acercarse desde 
otros lugares y con otras herramientas, como ya lo afirmaba el ańo 1996 Iván Carrasco, en su iluminador artículo "Hacia la comprensión de lo humano: literatura y antropología", sobre estrategias integradas de investigación. La lingüística es uno de esos flancos, porque no podemos acceder a los textos poéticos mapuches sin ese acercamiento a la lengua, no solo por el obvio motivo de la reflexión sobre la traducción sino porque la lengua comporta la cultura. Como señala María Catrileo (1992), la lengua es un rasgo cultural significativo en la determinación de una identidad y es además un punto de confluencia, de unión de su cultura espiritual y material y a veces "requisito esencial para su supervivencia", como un escudo protector que mantiene y trasmite los símbolos con los cuales configuran su visión de mundo y estructuran su pensamiento ("La Lengua mapuche como símbolo de identidad étnica"). Este maridaje entre lengua y cultura lo continuará refrendando en el tiempo bajo el sustento de investigadores como Boas, Sapir, Whorf, entre otros etnolingüistas. Catrileo ha señalado, en 2011, como lo recuerda Jorge Spíndola en una cita vertebral de su magistral tesis doctoral, "Los hechos lingüísticos son culturales y están determinados culturalmente" (Catrileo, 2011: 63).

Desde estas coordenadas retomamos el lenguaje poético con unos versos de Pedro Alonzo Retamal - Epu Mari Quiñe Ulcatun, 1969 del poema "Quila”:

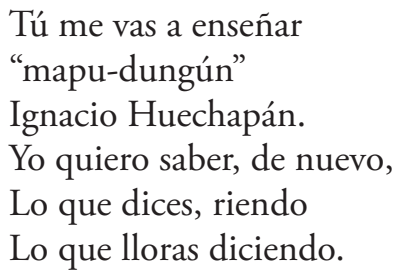

Queda claro en estos versos la conciencia de la pérdida, no solo de la lengua sino de la visión de mundo, y la urgencia de su reapropiación; asumiendo la idea que en el mapudungún no solo el humano es quien habla, sino todos los seres entran en diálogo. En esta misma línea, la poeta y profesora intercultural bilingüe María Isabel Lara Millapán ha señalado que aprender mapudungun es "también trascender en su lenguaje, comprender la cultura y las palabras que dialogan con la tierra y con el alma, con las palabras que nacen cuando son escuchadas" (fragmento del texto introductorio del libro Kimün: aprendiendo mapudungun a través de poesias y relatos).

En la vasta trayectoria de María Catrileo lo que se puede percibir como un hilo conductor es el reclamo lingüístico (dirá Pilar Álvarez) y un trabajo sistemático por la revitalización del mapudungún, y por ende, de la supervivencia de la cultura. Nos encontramos ante un proyecto académico que es también un proyecto de vida y un compromiso con su pueblo.

Respecto a los antecedentes del diccionario y las caracteristicas del investigador, podemos señalar que el diccionario, publicado por primera vez el año 95, tiene en su gestación una larga data. El año 1983 Catrileo publica el artículo "Etnografía y Lingüística: Introducción” (DLL 9). En este texto ya se vislumbra el trabajo que es requerido para poder elaborar un 
diccionario de esa envergadura que verá la luz doce años después. La preocupación por la etnografía la presenta desde entonces como una metodología válida, que permite describir las formas de vida de un grupo social, de una comunidad determinada, lo que constituye su cultura: "Esta nota revisa la historia de una relación: entre la lingüística y la antropología y la etnología, relación que sirvió para determinar el principio etnográfico según el cual el conocimiento de la cultura tiene directa relación con la lengua de esa cultura, de donde es posible deducir un método y un fundamento de análisis".

El año 1988 Catrileo Publica el artículo "Diseño de un diccionario lingüísticoetnográfico del mapudungun”, en Documentos Lingüísticos y Literarios 14, que sienta las bases lexicográficas de un diccionario de estas características, con la reflexión sobre los modos de recolección de datos, la variación lingüística más denotativa frente al análisis de relaciones semánticas entre ítems léxicos (connotativos); considerando dos aspectos, los usuarios y la metodología. Respecto a los primeros está pensado como un diccionario práctico multilingüe para estudiantes e investigadores, utilizando el grafemario del alfabeto unificado del mapudungún (ya que está basado en las grafías de la lengua castellana, es decir "sobre el conocimiento de escritura de la primera lengua aprendida"). Sobre la metodología, el diccionario no sigue un orden alfabético, sino de situaciones de comunicación y propone el trabajo de campo, etnográfico, a partir de la observación participante.

Sobre las caracteristicas particulares del investigador, que escribe libros de esta naturaleza, nos hacemos eco de las palabras de Iván Carrasco, refiriéndose a María Catrileo y su libro La lengua mapuche en el siglo XXI, extrapolable para este diccionario:

Hay libros que solo ciertas personas, con una determinada cultura global, intercultural y lingüística, con una particular experiencia de vida y sensibilidad por lo propio y lo ajeno, con un trabajo elaborado a través de muchos años de paciencia, amor y dedicación, son capaces de escribir. Estos libros necesitan una persona especial y una vida fundada en el compromiso por valores inalienables y una existencia destinada a escribirlo. Son el resultado de múltiples esfuerzos de memoria, de audición atenta, reflexión autocrítica y consulta oportuna, de confrontación con teorías... Estos libros no son producidos únicamente por procesos intelectuales, sino también vitales. Este libro de María Catrileo es uno de estos libros, un libro que solo María podía escribir.

Y como ha dicho Jacquelin Caniguan, sus trabajos constituyen un legado para las generaciones que vienen.

El Diccionario lingüístico etnográfico de la lengua Mapuche. Mapudungun-EspañolEnglish, fue editado por primera vez el año 1995; desde entonces ha tenido múltiples reediciones, y ahora ve la luz bajo la figura tutelar de Ediciones UACh, que amplía el corpus de su colección Austral Universitaria, en el área de Ciencias Sociales, Artes y Humanidades, siendo este su séptimo libro, desde el año 2014. Esta colección, como se señala en la página de la Editorial, "Constituye el eje central del catálogo corporativo de Ediciones 
Universidad Austral de Chile, representando en sus conceptos la adscripción geográfica y motivo intelectual que orienta el desarrollo de publicaciones arraigadas al conocimiento que se genera en nuestra casa de estudios superiores y al reconocimiento de autores nacionales e internacionales que contribuyan con sus obras a enaltecer el sello editorial". Entre los números de la colección austral universitaria, de esta área, podemos nombrar, por la cercanía con la facultad, los libros: Viajes a La Belleza del Espiritu. Cuatro Textos Dramáticos para la Difusión de la Ciencia, Roberto Matamala (2015); Tras el Ensayo Digital, Vicente Serrano (2015); Filosofía y Catástrofe. Nietzsche y la Devastación de la Política, Gonzalo Portales (2016); Vilém Flusser y la Cultura de la Imagen. Textos Escogidos, Breno Onetto M. (Estudio y Traducción) (2016), y ahora se suma el Diccionario lingüistico etnográfico de la lengua Mapuche. Mapudungun-Español-English, de María Catrileo Chiguailaf. Libro que merece el sitial de la Colección Austral Universitaria y cuyo sello se ve también enriquecido con él. Este diccionario, como hemos dicho, es del año 1995. Los trabajos de María de estos años serán un punto de inflexión del tratamiento de la lengua Mapuche por parte del Estado chileno. María Catrileo en esos años abría camino en los proyectos pilotos de educación intercultural bilingüe desarrollados en tres escuelas rurales y proponía, junto con Adalberto Salas y el Instituto Lingüístico de verano en el año 1986, el alfabeto unificado del mapudungún.

¿Cuándo y por qué se reedita un libro, este libro? Puede ser por interés editorial, el interés de los usuarios o el interés desde políticas ministeriales; todo apunta a la revitalización de la lengua. La reedición es traer al presente un texto de un pasado (reciente o remoto), algo así como "recordar". Reeditar este libro es entonces un cauce natural, como el movimiento entre recordar y actualizar, como un purrún vital, un baile monorrítmico sostenido en el tiempo, que permite el trance y la interiorización de la lengua y la cultura.

Cuáles son las Características particulares de este diccionario y qué han dicho los especialistas:

1. Lo primero que salta a la vista es que es trilingüe. Como ha escrito Claudio Wagner, en el Epílogo, "Es el primero en su género, en Chile, que tiene el carácter de trilingüe: mapudungun-español-inglés, lo que podrá facilitar la difusión de la primera lengua y, consecuentemente, de estudios comparativos en ámbitos hasta hoy de difícil acceso". Catrileo reconoce el desafío de trabajar con tres tipos de comportamiento lingüístico cultural y conjugar dos lenguas altamente estandarizadas, como el español y el inglés, con una no estandarizada como el mapudungún. Pilar Álvarez hablará en el prólogo del "gesto de amplitud universal (...) La lengua mapuche aparece así situada en anillos concéntricos y en su justo lugar de patrimonio universal”.

2. Está escrito por una hablante cuya lengua materna es el mapudungun. Pilar Álvarez-Santullano dirá respecto al texto, que "forma parte de una mirada interna, de una hablante que domina el mapuche como su lengua primera. No es solo léxico lo que hay aquí, sino las significaciones de las realidades materiales y simbólicas que conforman la vida y memoria de un pueblo".

3. La organización, no corresponde a un tradicional diccionario en orden alfabético, sino a partir de situaciones de comunicación. La opción por este modo es debido a que, señala María, "en la mente humana los términos lingüísticos suelen asociarse en torno a un tópico". 
"Este diccionario da cuenta del léxico más frecuente del mapudungun hablado en Chile (...). Nos invita a conocer la cultura mapuche, mediante situaciones de comunicación que atañen al hombre, su entorno familiar, la tierra, los animales, las enfermedades y los rituales." Cada una de ellas incluye un número de unidades léxicas en las categorías de sustantivo, verbo y adjetivo. Además incorpora al final un capítulo de Interjecciones y otro de terminología para designar las relaciones de parentesco.

4. Otra característica singular de este diccionario es la metodología. Bryan Harmelink, en el Epílogo, coloca el acento en "el carácter lingüístico-etnográfico de este diccionario que le hace sobresalir de otros diccionarios del mapudungun. Las frases ilustrativas son una fuente profunda de conocimiento cultural de la vida cotidiana de los mapuche". Respecto a las frases ilustrativas, este corpus de donde están extraídos los ejemplos, corresponden a los registros transcritos del trabajo de campo, pero también a transcripciones de textos como el de Pascual Cońa y los Estudios Araucanos de Rodolfo Lenz, entre otras recopilaciones más recientes, y atañen a situaciones de la vida cotidiana y rituales que ocurren en el entorno rural mapuche.

Veamos un ejemplo del ámbito de las enfermedades (kutran), que presenta a su vez, como entrada léxica, las posibilidades de tratamiento, de sanación, a partir de los remedios (lawén) de la medicina tradicional mapuche; es decir, un dominio de esos otros saberes que también transmite y comparte de manera generosa:

Kutranlongko: descrita como "dolor de cabeza". Frase ilustrativa, extraída de ese corpus de registros transcritos, es "Natrung kumey kutranlongko mew. Traducido como "el natre es bueno para el dolor de cabeza".

Otro ejemplo es Piukekutran: "enfermedad del corazón". Frase ilustrativa: Torongkil kumey piuwekutran mew. Traducida como "El toronjil es bueno para la enfermedad del corazón".

Un tercer ejemplo es Pafmu, descrita como "enfermedad de la cara producida por el cambio de temperatura o contraste de aire frío y caliente"; ejemplo interesante porque no tiene un equivalente en español en la medicina occidental. Frase ilustrativa: Palki kumey pafmu mew. "El palki cura el pafma".

Finalmente, en un gesto y guińo recursivo, y porque en este Diccionario lingüísticoetnografico se perfila y se asoma la autora, quisiera terminar con los versos ya leídos de Pedro Alonzo Retamal, levemente modificados:

Tú nos vas a enseñar "mapu-dungún"

María Catrileo.

queremos saber, de nuevo,

Lo que dices, riendo

Lo que lloras diciendo.

Chaltumay. 


\section{OBRas CiTADAS}

Carrasco, Iván. 1996. "Hacia la comprensión de lo humano: literatura y antropología”. En: Marta Rodríguez y Miguel Farías. Eds. Investigación Multidisciplinaria. Estrategias integradas en investigación en lingüistica, literatura y disciplinas afines. Santiago: Universidad de Santiago de Chile.

Catrileo, María. 1983. “Etnografía y Lingüística: Introducción”. Documentos Lingüisticos y Literarios 9: 47-52.

Catrileo, María. 1988. "Diseño de un diccionario lingüístico-etnográfico del mapudungun”. Documentos Lingüisticos y Literarios 14: 31-36.

Catrileo, María. 1992. "La Lengua mapuche como símbolo de identidad étnica”. Actas Coloquio Sobre Culturas Indígenas: lenguaje e identidad. Temuco: Conicyt, Pontificia Universidad Católica de Chile y Universidad de la Frontera.

Catrileo, María. 1995. Diccionario Lingüistico-Etnografico de la Lengua Mapuche. Santiago: Andrés Bello.

Catrileo, María. 2010. La lengua mapuche en el Siglo XXI. Valdivia: Universidad Austral de Chile.

Molina V., Ricardo \& María Pía Poblete S. 2004. “Entrevista a María Catrileo”. Revista Austral de Ciencias Sociales 8: 51-72.

Nahuelpan, Héctor. 2013. "Las 'zonas grises' de las historias mapuche. colonialismo internalizado, marginalidad y políticas de la memoria”. Revista Historia Social y de las Mentalidades. 1 (17): 9-31.

VVAA. 2010. "Homenaje a la profesora María Catrileo con ocasión de la presentación de su libro La lengua mapuche en el siglo XXI, en el acto organizado por la Facultad de Filosofía y Humanidades de la Universidad Austral de Chile, el jueves 19 de agosto de 2010”. Estudios Filológicos 46: 173-182. 
